\title{
Dopant-site dependent properties of nitrogen and boron doped spherical nanodiamond particles from first-principle DFT simulation
}

\author{
M. Kavosh Tehrani ${ }^{1, a}$ and M. Heidari Saani ${ }^{1,2}$ \\ ${ }^{1}$ Department of Physics, Malek-Ashtar University of Technology, Shahin Shahr, P.O. Box 83145-115, Shahin Shahr, Iran \\ 2 Optoelectronic Industry, P.O. Box 19575-199, Artesh Highway, Tehran, Iran
}

Accepted: 5 September 2011

Published online: 28 September 2011 - (C) EDP Sciences 2011

Eur. Phys. J. Appl. Phys. 55, 10402 (2011), DOI: 10.1051/epjap/2011110022

An error occurred during the publication process in the Aims and Scopes sections of the contents: This article should be under section Nanomaterials and Nanotechnologies.

We apologize for this inconvenience.

${ }^{a}$ e-mail: m_kavosh@mut-es.ac.ir 